\title{
Preparation and Characterization of Free Radical Photopolymer with Carbon Black Nano-particle
}

\author{
Wen-Tung Cheng ${ }^{\star}$ and Wei-Ting Yeh \\ Department of Chemical Engineering, National Chung Hsing University, \\ 250 Kuo Kaung Rd., Taichung 402, Taiwan, R. O. C.
}

\begin{abstract}
The aim of this paper is to prepare and characterize the free radical photopolymer with carbon black nano-particles. At first, carbon black nano-powder was wetted by the co-solvent composed from propylene glycol mono-methyl ether acetate with normal butyl alcohol lowing surface tension to enhance the permeability of agglomerated carbon black, and then polymeric dispersant was added to stable carbon black nano-particles in liquid after milling process. The dispersed solution was taken out to blend with cresol novolac epoxy acrylate, dipentaerythritol pena-hexa-acrylate, ethanone, 1-[9-ethyl-6- (2-methylbenzoyl)9H-carbazole-3-3-yl]-, 1-(O-acetyle oxime), and 2-benzl-2-N, N-dimenthylamino-1(4-morpho-linophenyl) butanone to form the free radical type photosensitive resin with carbon black nano-particles. In order to understand the state of the carbon black nano-particle dispersion in the solution and photosensitive resin, respectively, the dynamic laser light scattering particle analyzer, transmission electron microscopy, Brunauer-Emmett-Teller, and atomic force microscopy were applied. Additionally, polymerizing quantification and lithographic performance of photosensitive resin with carbon black nano-particle were carried out by differential photo calorimeter and wedge curve analysis, respectively, in this study.
\end{abstract}

Keywords : preparation and characterization, free radical, photopolymer, carbon black, nano-particle

\section{Introduction}

Nanometer size particles present many properties that are both quantitatively and qualitatively different from their respective bulk materials and from the discrete atomic or molecular species from which they are derived [1]. The increased surface area of nano-particle has long been exploited to optimize the optical character, electrical conductivity, and heat dissipation of polymeric film [2].

The color filter is one of important elements for thin film transistor liquid crystal displays (TFTLCD) because it directly defines the color image quality of the display. Generally, a color filter consists of a large number of color triplet, each comprises three colors of pixels, namely, red, green, and blue, formed on a transparent substrate. In order to enhance the contrast of the color display, the light-shading regions of predetermined width, which is call the black matrix due to its black color on screen, are formed between sub-pixels [3]. Additionally, a black matrix having high light shad-ability is required to prevent deterioration in image quality resulting from leakage current of the thin film transistors [4-6]. In short, it is essential that a black matrix on color filter not only has sufficient light-shielding ability but also be formed with high resolution to obtain a high aperture ratio and high contrast in color TFTLCD.

Most of the conventional color filters employed a thin metal film and photolithographic process including etching process to fabricate the black matrix. The metals used for black matrixes involve $\mathrm{Cr}, \mathrm{Ni}$, and $\mathrm{Al}$, which are formatted as thin film by means of vacuum sputtering deposition method. In addition, the photolithography is required to fabricate the pattern of photo-resist as mask protecting the metal thin film to define black matrix during etching process.

Cr-deposited films have so far been used for black matrices on the color filter [7]. However, although

Received September 25, 2006

Accepted October 30, 2006 
black matrices comprising a $\mathrm{Cr}$-deposited film are excellent in light-shielding ability, they have several problems: (1) ghost image is caused as they have high reflection coefficient leading to the deterioration of visibility; (2) $\mathrm{Cr}$ used in a black matrix is complicated and expensive; and (3) the disposal of $\mathrm{Cr}$ waste solutions is a pollution problem [8-11]. Therefore, black matrices made from a photosensitive resin film having dispersed therein the black pigment and patterned upon a design have been researched [12]. The photosensitive resin forming black matrices have low reflection coefficient and environmental friendly as well as manufacture inexpensively.

Carbon black is widely used as the black pigment in photosensitive resin. The carbon black can be specified as the different classes according to its primary particle size, specific surface area and volatile content [13], which offers superior heat, light and chemicals resistances [14]. Finer dispersion of the carbon black is essential to obtain high electric resistance and high uniformity of black matrix film [15]. Nanometer size particle exhibits higher specific surface area than the bulk phase [16]. Therefore, to improve the light-shad ability of black matrix, it is preferable to apply smaller carbon black particles dispersing in polymeric resin [17].

Producing fine particle size and narrow particle size distributions in the solution is a significant challenge. Therefore, optimum utilization of both milling process and chemical technologies is necessary to most efficiently achieve stable dispersions with the target particle size characteristics. In the mechanical dispersion methods, shearing force is usually employed to disperse the aggregated primary particles into a separation unit and fine secondary particle. It should have enough mechanical energy to separate aggregating primary particles. Increasing grind time could supply enough mechanical energy to disperse primary particles into nanometer scale size of secondary particles in liquid [18, 19].

For black matrix, the free radical type photosensitive resin normally consists of multi acid grouped polymer, reactive monomer, photo-initiator, and carbon black [20], which had a problem that the carbon black particles are prone to flocculation reducing the storage stability [21-23]. In addition, to achieve high optical density of black matrix, the free radical type photosensitive resin was need to contain carbon black in high loading content leading to insufficient hardening in the interface between the black resin film and the substrate narrowing the development latitude.

The object of this work studies on preparation of the free radical photosensitive resin with carbon black nano-particles, at low weight percentage, for a black matrix, which may display high resolution in line width, low electrical conductivity, and high optical density. The purpose is begin with that carbon black nano-powders which average primary particle sizes are $24 \mathrm{~nm}$ and $15 \mathrm{~nm}$, respectively, as specified in Table 1, are wetted by the co-solvent composed from propylene glycol mono-methyl ether acetate (hereinafter abbreviated as PGMEA, manufacturing by Lancaster) with normal butyl alcohol (manufacturing by Fisherchemical), decreasing surface tension to enhance the permeability of agglomerated carbon black particles, and then polyester/polyamine polyester/ polyamine dispersant (that is HYPERMER ${ }^{\circledast}$ PS2 and PS3, manufacturing by Uniqema, a member of ICI group) is added to stable carbon black nano-particles in solution after milling process. Finally, the dispersion solution of carbon black nano-particles is blended with carboxylated cresol novolac acrylated (hereinafter abbreviated as $39 \mathrm{~S}$, manufacturing by Chembridge International Corp., Taiwan, having an weight-average molecular weight, $\mathrm{Mw}=4000 \mathrm{~g} / \mathrm{mole}$, and acid value of $56 \pm 2 \mathrm{KOH} \mathrm{mg/g}$ ), dipentaerythritol pena-hexa-acrylate (hereinafter abbreviated as DPHA), and photo-initiators (mixing CGI 242 and Irgacure 369, manufactured by Ciba Specialty Chemicals, having a general structural

Table 1 The information of the carbon black examined in this study.

\begin{tabular}{lcc}
\hline & \multicolumn{2}{c}{ Carbon Blacks } \\
\cline { 2 - 3 } \multicolumn{1}{c}{ Items } & Mogul $\mathrm{L}$ & ${\text { Monarch- } 900^{2}}^{2}$ \\
\hline Primary particle diameter $(\mathrm{nm})$ & 24 & 15 \\
BET specific surface area $\left(\mathrm{m}^{2} / \mathrm{g}\right)$ & 119 & 252 \\
Volatile $(\mathrm{wt} \%)$ & 5 & 2 \\
DBP $\left(\mathrm{cm}^{3} / 100 \mathrm{~g}\right)$ & 60 & 70 \\
Color ration $(\mathrm{wt} \%)$ & 131 & 151 \\
\hline Products of Cabot Corporation. & & \\
${ }^{2}$ Hereinafter abbreviated as M-900. & &
\end{tabular}


Table 2 The information of photo-initiators examined in this study [1]

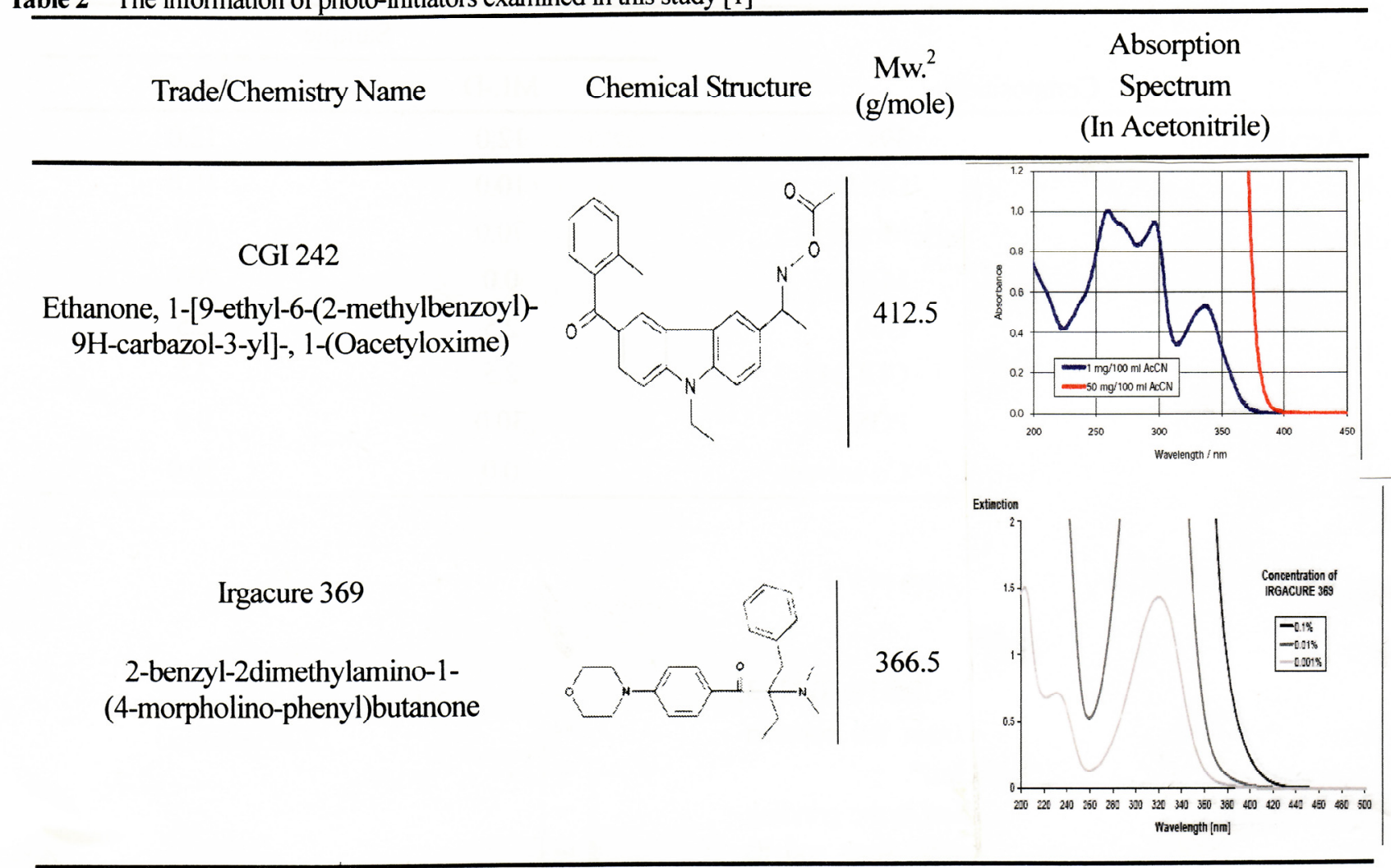

${ }^{1}$ Provided by Ciba Specialty Chemicals

${ }^{2} \mathrm{Mw}$ expresses weight-average molecular weight

formulas as shown in Table 2) to form the free radical type photosensitive resin with carbon black nano-particles, at low weight percentages, intending to obtain high resolution of black matrix with higher optical density but lower electrical conductivity.

The dispersion of carbon black nano-particle and performance of photosensitive resin are to be determined by employing dynamic laser light scattering particle analyzer (Brookheven 90 Plus Particle Sizer), transmission electron microscopy (abbreviated as TEM, JEOL JEM-1200CX), atomic force microscopy (abbreviated as AFM, SEIKO SPA-400), Brunauer-Emmett-Teller (abbreviated as BET, Micro-meritics ASAP 2010), transmission densitometer (Gretag Macbeth ${ }^{\mathrm{TM}}$ GRETAG D200-11), high resistivity meter (Simco Trustat ST-3), differential photo calorimeter (hereinafter abbreviated as DPC, TA Instruments-Dupont 930), and wedge curve analysis, respectively. To our knowledge, such an extensive study on this approach has never been conducted, although resin black matrix for color liquid crystal display have been studied in detail $[5,24,25,26]$.

\section{Experimental}

\subsection{Dispersion of carbon black nano-particles}

The Mogul L and M900 carbon blacks as well as PS2 and PS3 polymeric surfactants were used. Dispersion of carbon black nano-particle in liquid was prepared using a mechanical dispersion method performed by Red Devil 5400-HB, USA, with steel ball

Table 3 The formula of carbon black dispersion in the solution

\begin{tabular}{lccccccc}
\hline \multirow{2}{*}{ Sample } & \multicolumn{2}{c}{ Carbon Blacks } & \multicolumn{2}{c}{ Dispersant } & \multicolumn{2}{c}{ Solvent } & \multirow{2}{*}{$\begin{array}{c}\text { Amount of Carbon } \\
\text { Black }\end{array}$} \\
\cline { 2 - 7 } & Mogul L & M-900 & PS2 & PS3 & PGMEA & Co-solvent & Black \\
\hline ML & 20 & 0 & 6 & 0 & 75 & 0 & $19.8 \mathrm{wt} \%$ \\
M9 & 0 & 15 & 0 & 9 & 0 & 75 & $15.1 \mathrm{wt} \%$ \\
\hline
\end{tabular}

Unit : gram

Co-solvent : PGMEA/1-Butanol $=2$ 
Table 4 The composition of free radical photo-resist with carbon black nano-particle

\begin{tabular}{lcccc}
\hline & & \multicolumn{2}{c}{ Sample } \\
\cline { 3 - 5 } & Compositions & & ML-D & M9-D \\
\hline Acrylate resin & 39s & 12.0 & 12.0 \\
Monomer & DPHA & 10.0 & 10.0 \\
Dispersed solution & of carbon & black Mogul L & 70.0 & 0.0 \\
nano-particle & M-900 & 0.0 & 70.0 \\
Photo-initiator & I369 & 2.5 & 2.5 \\
\multirow{2}{*}{ Solvent } & CGI-242 & 2.5 & 2.5 \\
& PGMEA & 30.0 & 0.0 \\
\hline
\end{tabular}

unit : gram

Co-solvent : PGMEA/1-Butano ration of $1 / 2$

in diameter of $2 \mathrm{~mm}$. Two formulas, as listed in Table 3, were dispersed for 16 hours to obtain the solution containing carbon black nano-particles.

To evaluate the effect of dispersion in the grinding process, the secondary average particle sizes and its distribution of carbon black are analyzed using TEM and dynamic laser scattering particle analyzer; as well as the specific surface area of carbon black is measured by BET. For dynamic laser scattering particle analysis, the dispersion of Mogul L and M-900 carbon blacks were respectively diluted with PGMEA and co-solvent composed from the butanol/PGMEA ratio of $1 / 2$ to $1 / 3000$ of concentration in dispersed solution. For evidence, the sample is measured by TEM through dropping on the copper net and drying naturally. Furthermore, BET is used to estimate the adsorption volume or weight of the nitrogen adsorbed on the surface of dispersed carbon black after the grinding process and drying at $130^{\circ} \mathrm{C}$ for 2 hours, as well as treating by $300^{\circ} \mathrm{C}$ for 2 hours to remove dispersant.

Additionally, these solutions were coated on the glass substrate by means of a spin coater (Synrex SSP-01A, Taiwan) in a film thickness of $1.0 \mu \mathrm{m}$ (measuring by Taylor-Hobson Talystep) and dried at $100^{\circ} \mathrm{C}$ in oven for $30 \mathrm{~min}$ for the measurement of AFM with tapping mode.

\subsection{Preparation of negative photo-resist with carbon black nano-particles}

According to the formula, as listed in Table 4, the dispersed solution of carbon black nano-particle was charged to photosensitive resin composed of $39 \mathrm{~S}$ polymer, DPHA monomer, and mixed photo-initiators of

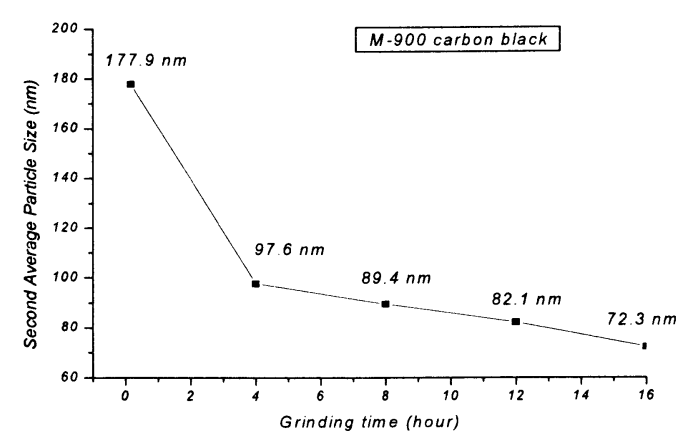

(a)

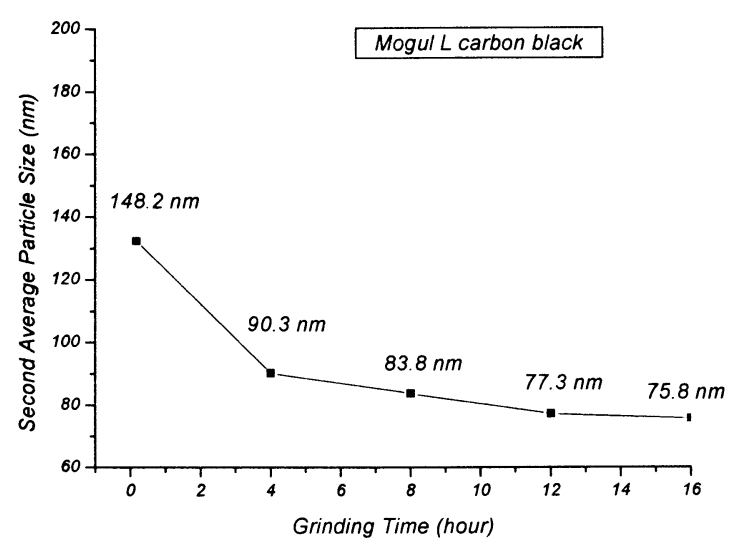

(b)

Fig. 1. The secondary average particle size of the carbon black at the loading amount of (a) $20 \mathrm{wt} \%$ Mogul L and (b) $15 \mathrm{wt} \%$ M900, respectively, as function of the grinding time 


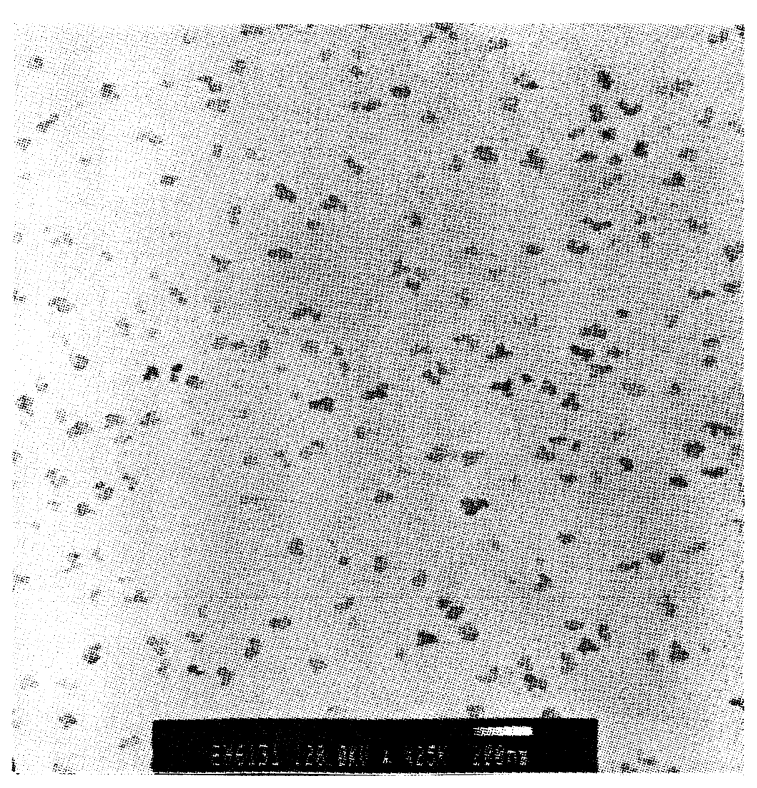

(a)

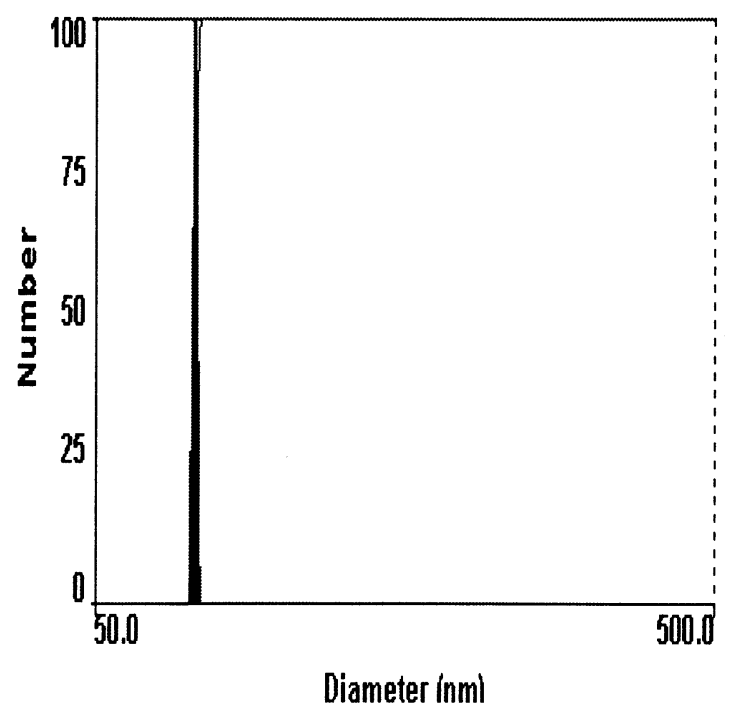

(b)

Fig. 2. (a) TEM graph and (b) secondary particle distribution of $20 \mathrm{wt} \%$ Mogul L carbon black in liquid after grinding for 16 hours.

Irgacure-369 and CGI-242 to form free radial type black photo-resist. As shown in Table 2, CGI-242/Irgacure 369 mixture can be used to enhance UV light adsorption at wavelengths from $250 \mathrm{~nm}$ to $320 \mathrm{~nm}$ in photosensitive resin with carbon black nano-particle.

The prepared black photo-resist was coated onto a glass substrate in dimensions of $5 \times 5 \mathrm{~cm} / \mathrm{cm}$ by a spinner with 500 r. p. $m$ at dispersed stage and 2500 r. p. m. for final stage, followed by drying in oven at $130{ }^{\circ} \mathrm{C}$ for

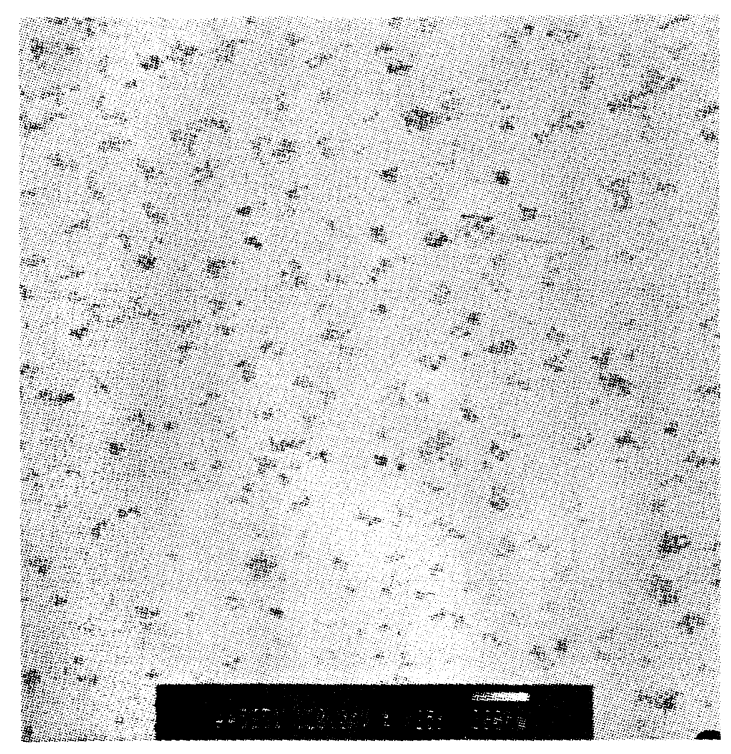

(a)

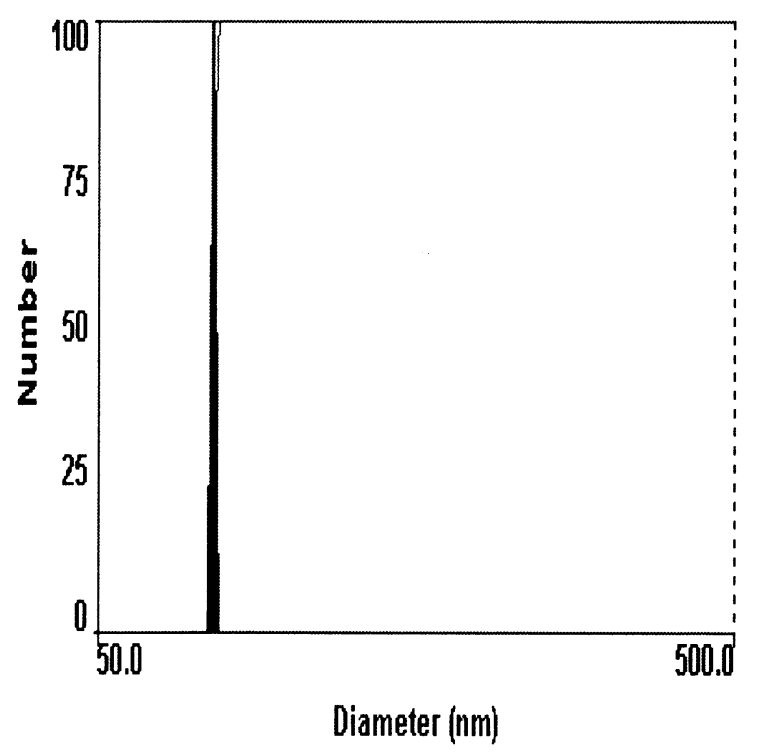

(b)

Figure. 3. (a) TEM graph and (b) secondary particle distribution of $15 \mathrm{wt} \%$ M900 carbon black in liquid after grinding for 16 hours.

$30 \mathrm{~min}$. The coated films of black photo-resist were then taken to measure optical density by transmission densitometer and surface electric resistance by high electric resistance meter. In addition, DPC is applied to investigate reactivity of free radical photosensitive resin with carbon black nano-particle in the different dosage of photo-initiator. The procedures of DPC analysis were 

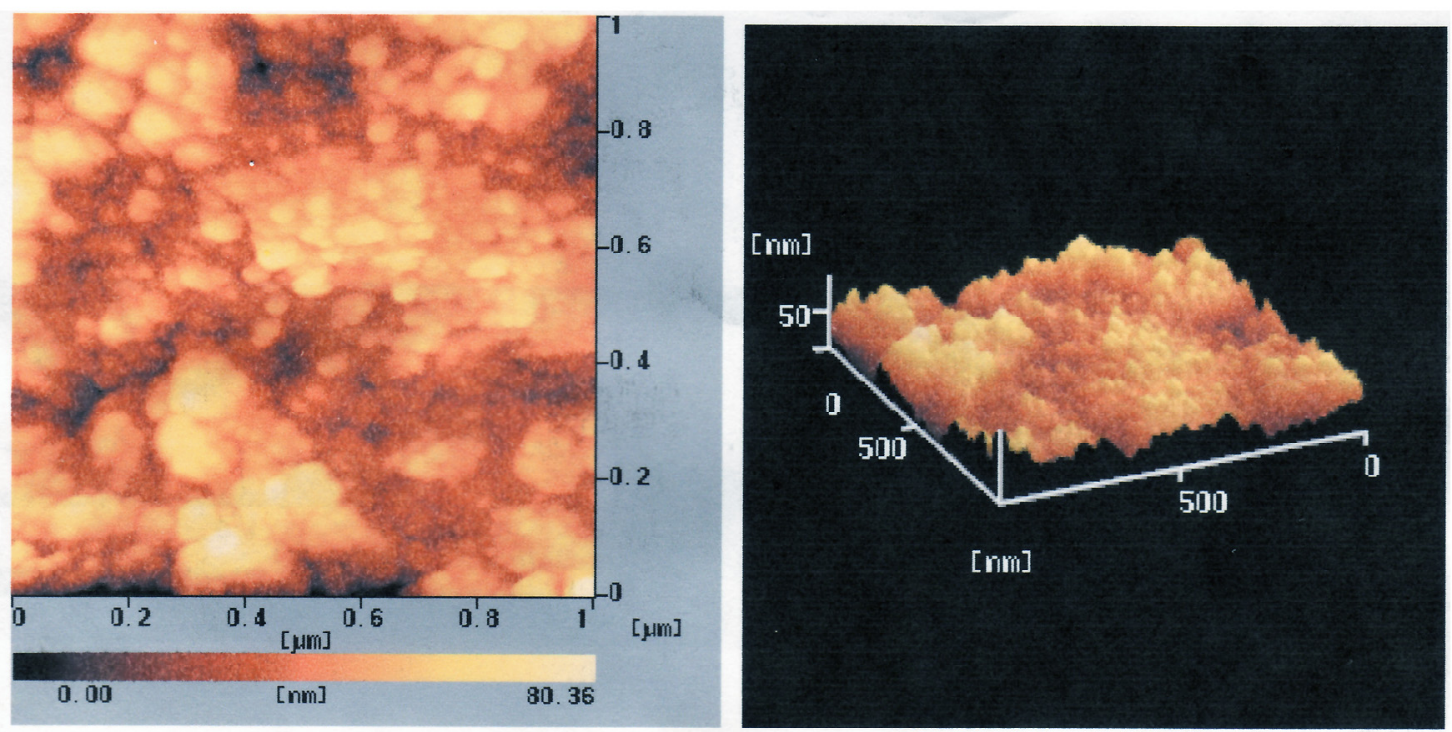

(a)
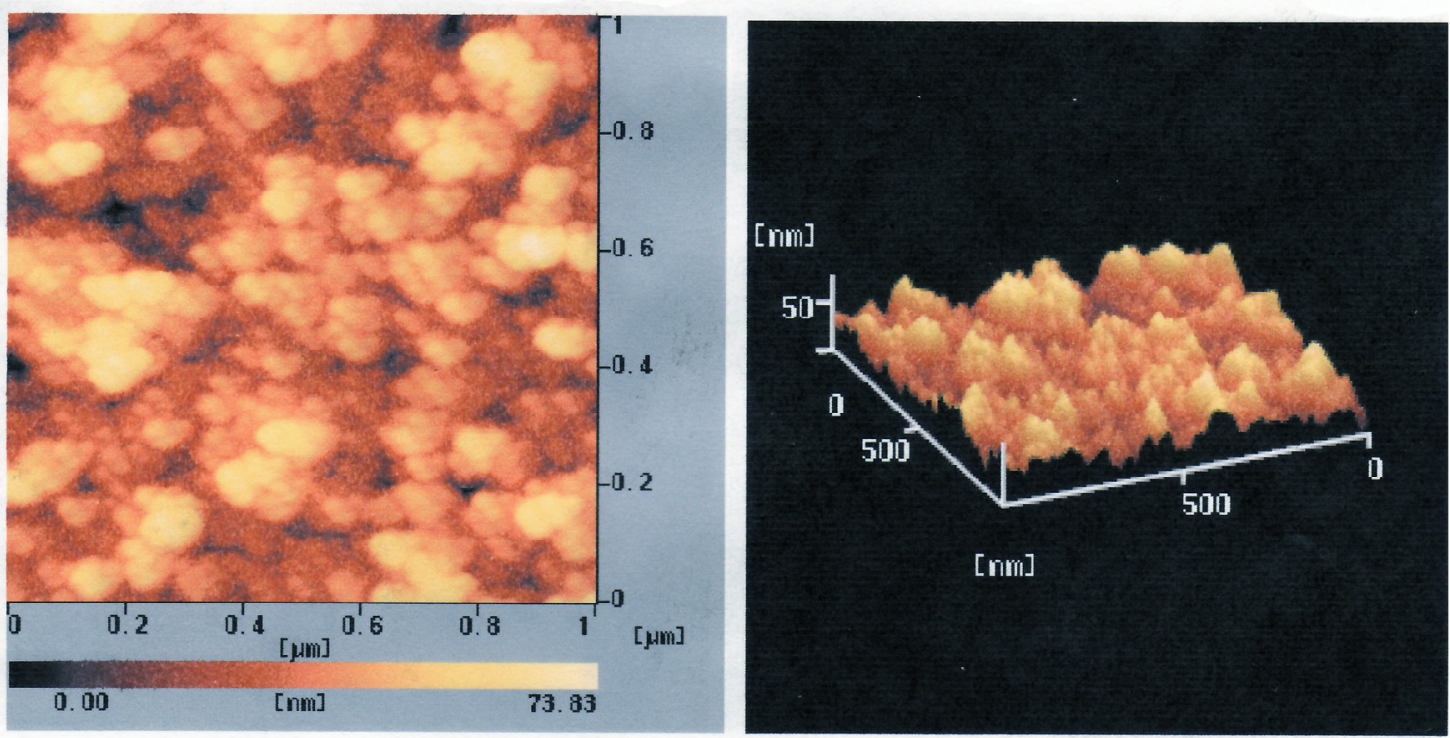

(b)

Fig. 4. The AFM morphology and 3D graph of coated film made from $20 \mathrm{wt} \%$ Mogul L carbon black in the solution for grading time of (a) $10 \mathrm{~min}$ and (b) 16 hours, respectively.

carried out as follows: (1) the power supply was opened to turn on the UV-light; (2) the photometer was used to regular the UV intensity as $5 \mathrm{~mW} / \mathrm{cm}^{2}$ at the wavelength of $365 \mathrm{~nm}$; and (3) the free radical type black photo-resist was taken out about $1 \mathrm{mg}$ and putted into the aluminum pan and radiated at $30^{\circ} \mathrm{C}$ for $5 \mathrm{~min}$ isothermally.

\subsection{Characterization of negative photo-resist with carbon black nano-particles}

To evaluate lithographic performance of free radical type black photo-resist, the wedge curve was made. At first, the free radical type black photo-resist was coated onto a glass substrate in dimension of $5 \times 5$ $\mathrm{cm} / \mathrm{cm}$ by means of a spinner with $500 \mathrm{r} . \mathrm{p} . \mathrm{m}$ at dispersed stage and 2500 r. p. m. at final stage following by pre-baking in oven at $110{ }^{\circ} \mathrm{C}$ for $10 \mathrm{~min}$. The coated film of free radical type black photo-resist was then 

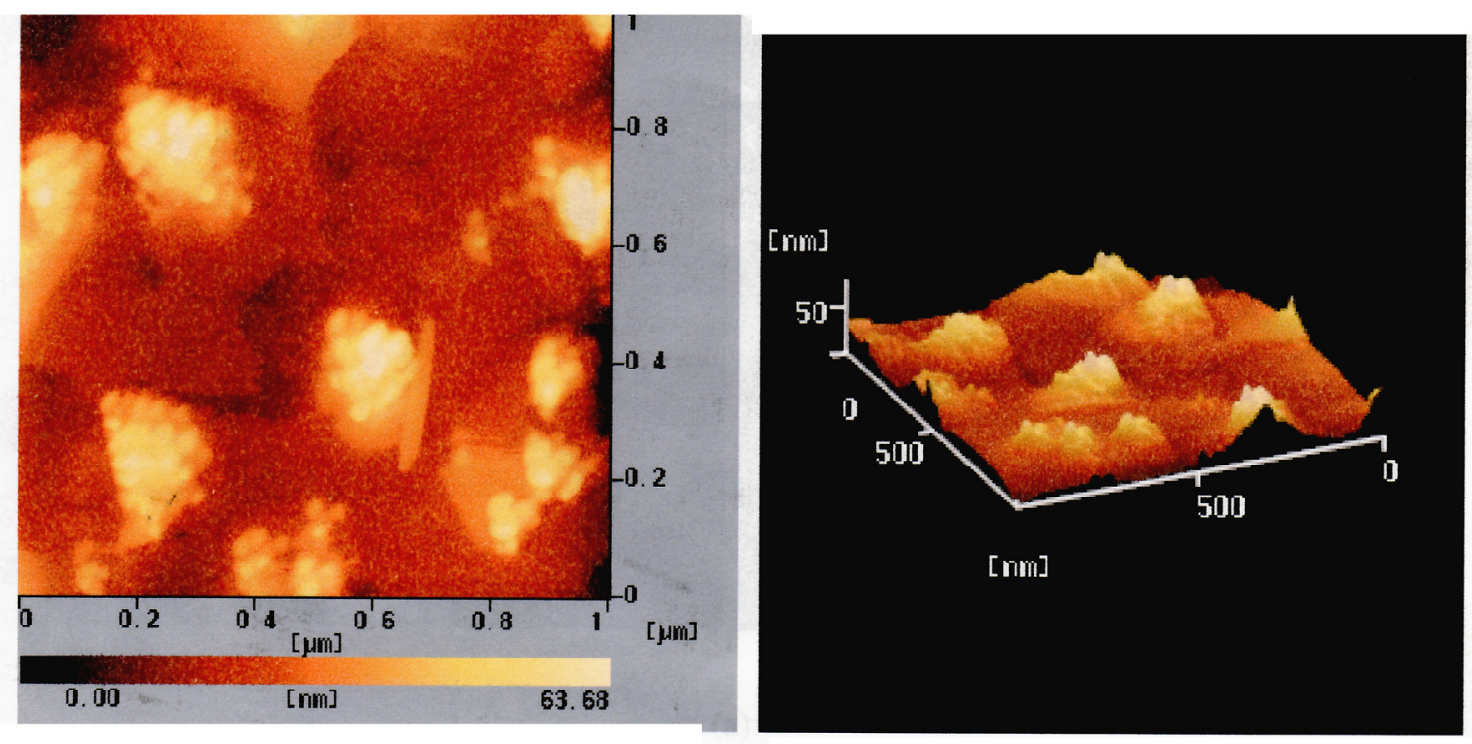

(a)
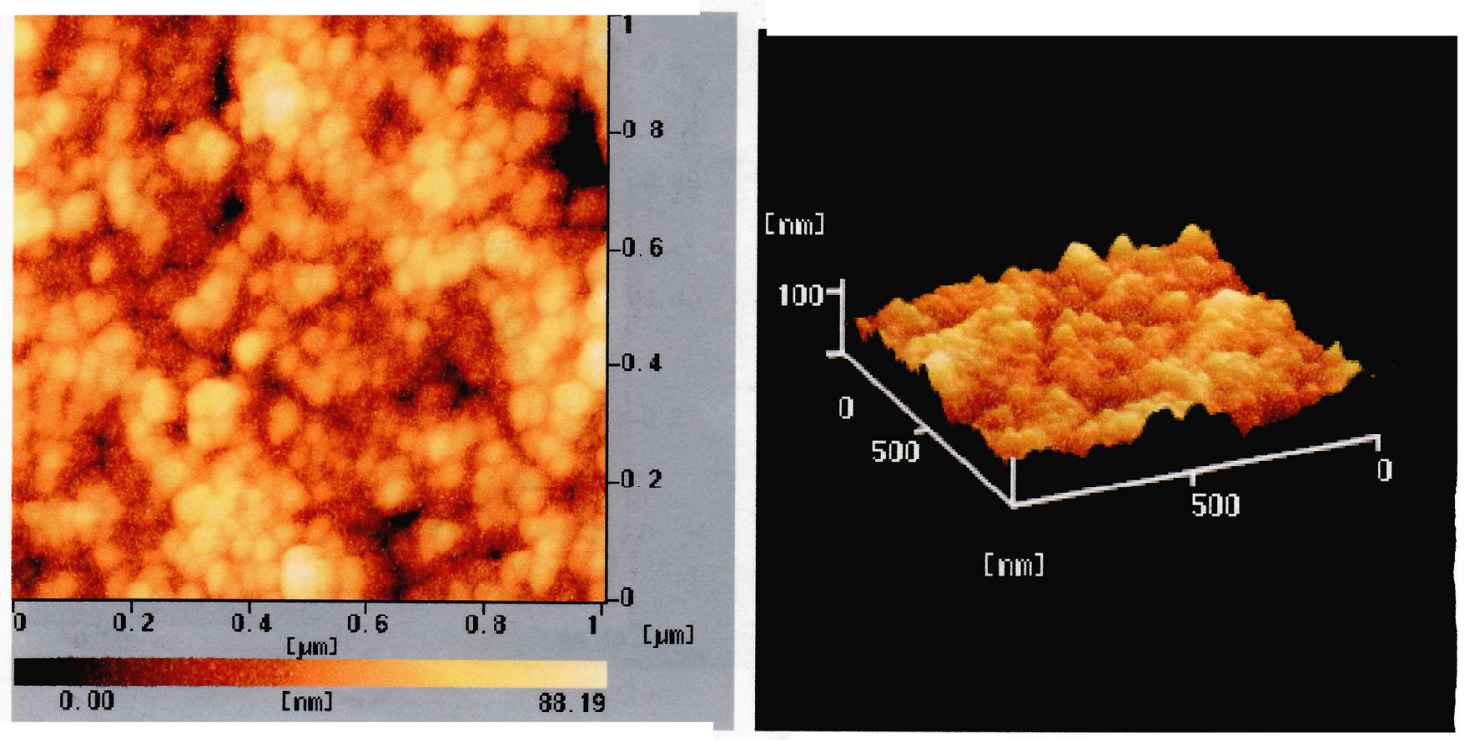

(b)

Fig. 5. The AFM morphology and 3D graph of coated film made from $15 \mathrm{wt} \% \mathrm{M} 900$ carbon black in the solution for grading time of (a) $10 \mathrm{~min}$ and (b) 16 hours, respectively.

exposed by UV-light (wavelengths from $250 \mathrm{~nm}$ to $480 \mathrm{~nm}$, EFOS 3000/BLX312) in the dose ranging from 0 to $300 \mathrm{~mJ} / \mathrm{cm}^{2}$ every a step of $25 \mathrm{~mJ} / \mathrm{cm}^{2}$ followed by spray type of development with $0.2 \mathrm{wt} \% \mathrm{KOH}$ in de-ionic water at $25^{\circ} \mathrm{C}$ for 20 second. Finally, the pattern of free radical type black photo-resist was post-baked in oven at $130^{\circ} \mathrm{C}$ for $30 \mathrm{~min}$ and observed by optical microscope (Olympus DP-11, Japan) at $500 \mathrm{X}$ of resolution in line width, which film loss was detected by Taylor-Hobson Taylor step.

\section{Results and Discussion}

\subsection{Dispersion of Carbon black nano-particle}

An effective method for increasing the carbon black dispersion is by milling in solution |27|. Critical to this method is the separation of carbon black nano-particle in liquid, which may be achieved by surfactant adsorption at the carbon black surface, surface treatment, or a combination of both. Lowering the 


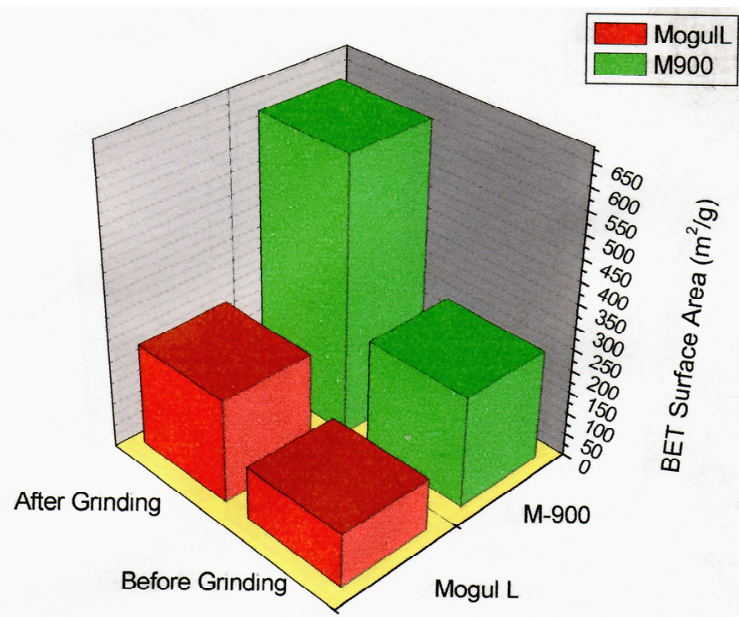

Fig. 6. Comparison of surface areas of Mogul L and M 900 carbon blacks before and after grinding for 16 hours.

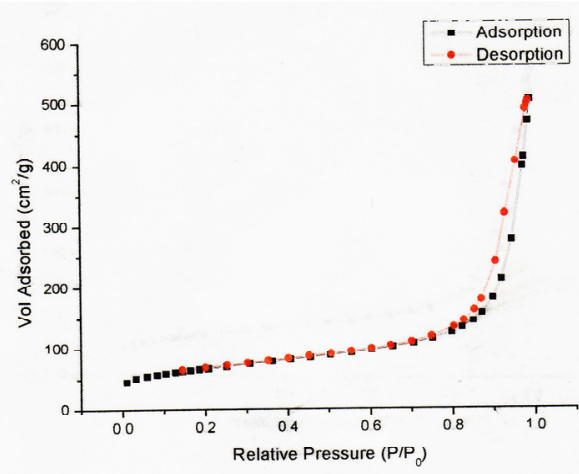

Before dispersing

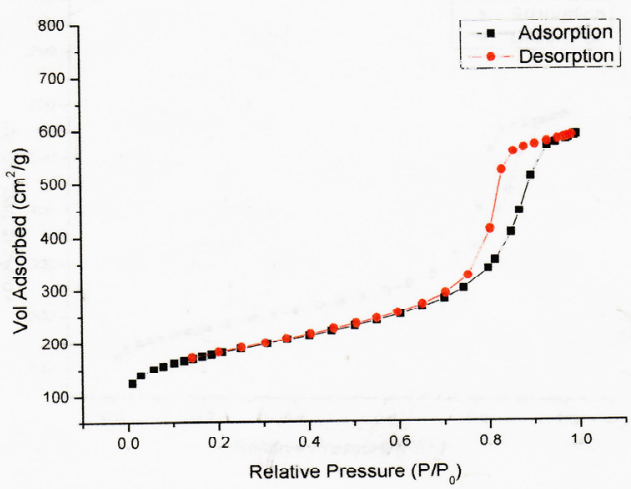

Before dispersing surface tension of the carbon black prevents aggregates from forming, and improves the wet-ability of carbon black by polymeric surfactant. As measured from dynamic light scattering particle analyzer, Fig. 1 shows the aggregated primary particle sizes of Mogul $\mathrm{L}$ and M-900 carbon blacks both reducing with increasing grind time in the presence of surfactants of PS2 and PS3, respectively. This figure also displays the secondary average particle size of Mogul L carbon black is smaller than that of M-900 pigment at the grinding time for 12 hours, while the increasing grinding time, the secondary average particle size of M-900 pigment is smaller than that of Mogul L carbon black in the solution because the smaller primary particles of carbon blacks with higher packaging density are difficult to apart and need of high impact energy to separate aggregated primary particles [28]. For evidence, Figs 2 and 3 exhibit TEM pictures of Mogul L and M900 carbon blacks, respectively, after grinding for 16 hours. As observed in graphs, the

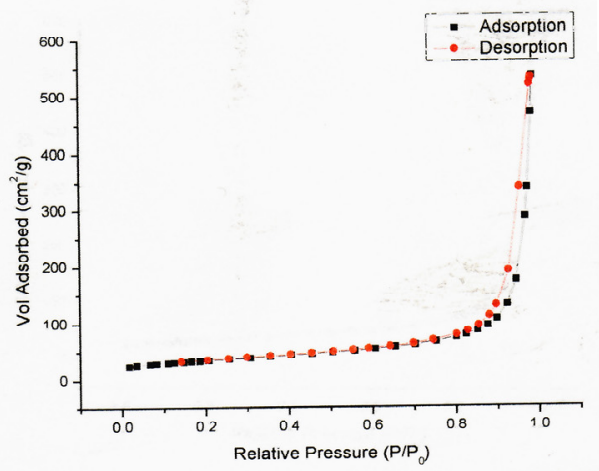

After dispersing

(a)

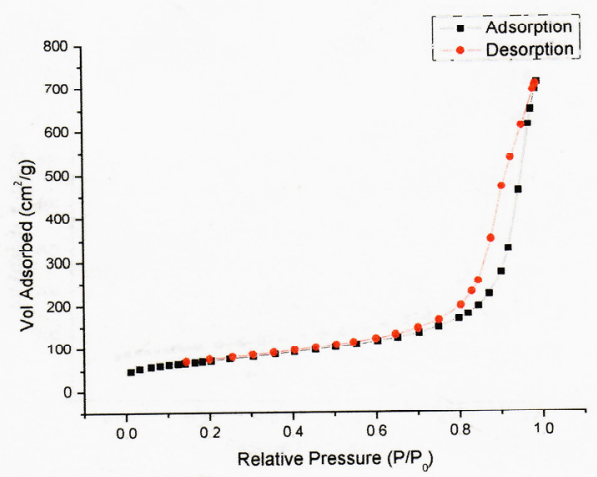

After dispersing

(b)

Fig. 7. Hysteretic loops of nitrogen absorption and de-sorption on (a) Mogul L and (b) M900 carbon blacks, respectively, before and after dispersing for 16 hours. 


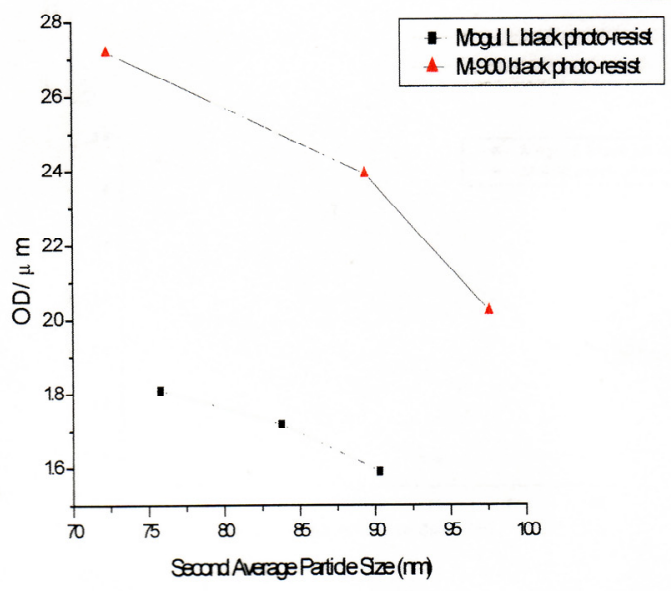

Fig. 8. Optical density varying with the secondary average particle size in free radical type photo-resist containing $10 \mathrm{wt} \%$ Mogul L and M900 carbon blacks, respectively.

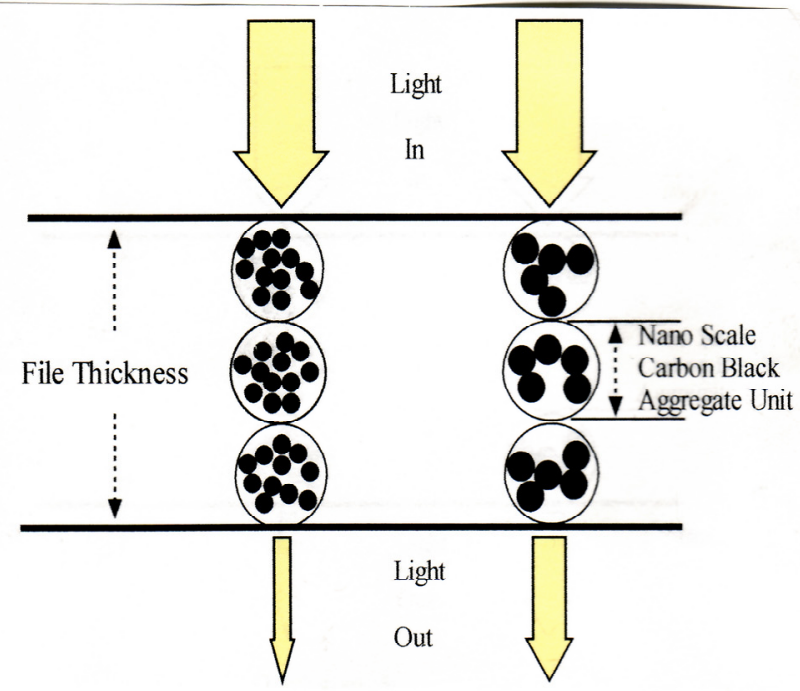

Fig. 9. The sketched mechanism for the effects of primary average particle size and secondary average particle size on light shielding.

secondary average particle size of Mogul L carbon black is $75.8 \mathrm{~nm}$ while $\mathrm{M}-900$ is $72.3 \mathrm{~nm}$, which distributions are both uniform in the solution.

With tapping mode, AFM is also taken to probe the morphology of the film coated by spinning the dispersion solution of carbon black on the glass substrate (Corning 1737) varying with milling time. Figs. 4 and 5 are respectively used to demonstrate variation of the carbon black dispersion with time for $20 \mathrm{wt} \%$ of Mogul L and $15 \mathrm{wt} \%$ of M900 in liquid. In figures, the morphology and 3D graph of the film made from the solution of M900 carbon black can be clearly observed more aggrcgation than that from Mogul L carbon black because of smaller avcrage primary particle with low structure hard to be separated at initial stage as grinding for $10 \mathrm{~min}$.

As grinding time for 16 hours, the surfaces of coated film made from dispersed solutions of Mogul L and M900 carbon blacks both reveal uniform and flatness, which may be used to explain that the aggregated primary particle size of carbon black has

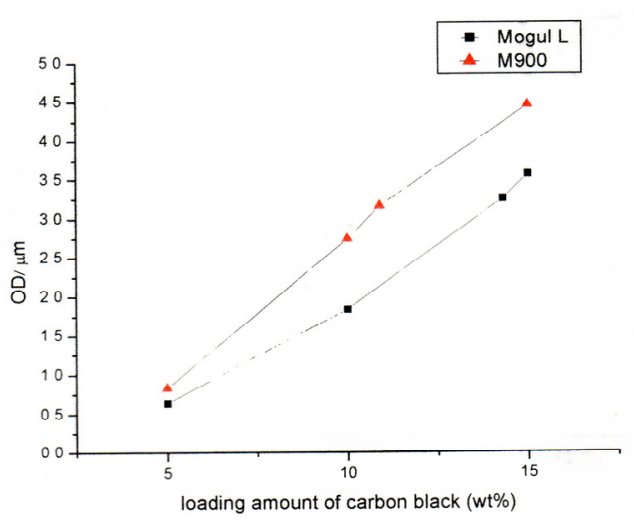

Fig. 10. Optical density varying with the loading amount of Mogul L and M900 carbon blacks in the secondary average particle sizes of $75.8 \mathrm{~nm}$ and $72.3 \mathrm{~nm}$, respectively, in free radical type photosensitive resin.

been reduced into smaller one in liquid.

For BET analysis, nitrogen volume or weight adsorption on the carbon black can be obtained to calculate specific surface area of particle [29].

In this work, the sample is needed to evaporate solvent from the dispersion solution of carbon black at $130{ }^{\circ} \mathrm{C}$ for 2 hours and remove the dispersant on the carbon black at $300^{\circ} \mathrm{Cfor} 2$ hours. As shown in the results, .a specific surface area of Mogul $\mathrm{L}$ pigment is increased to $234 \mathrm{~m}^{2} / \mathrm{g}$ from $119 \mathrm{~m}^{2} / \mathrm{g}$ after grinding process, and that of M-900 carbon black is remarkably enlarged to $630 \mathrm{~m}^{2} / \mathrm{g}$ from $252 \mathrm{~m}^{2} / \mathrm{g}$, as illustrated in Fig. 6, due to the aggregated primary particle of carbon blacks dispersed by means of milling process in the presence of polymeric dispersant into small one.

Furthermore, Fig. 7 compares the isotherm hysteretic loops of nitrogen adsorption and desorbing on carbon black before and after grinding process. In figure, before milling, it is observed that isotherm curves of nitrogen absorption and desorbing on carbon black are clearly difference because of the pore channel formed by aggregated primary particle in arrear with nitrogen desorbing; whereas the arrearage phenomena is obviously reduced when the aggregated primary particles are crashed by milling to reduce the pore channel formed by packing primary particles, which results in isotherm curve of nitrogen absorption is closed to that of nitrogen desorbing on carbon black after grinding for 16 hours.

\subsection{Opto-electrical properties}



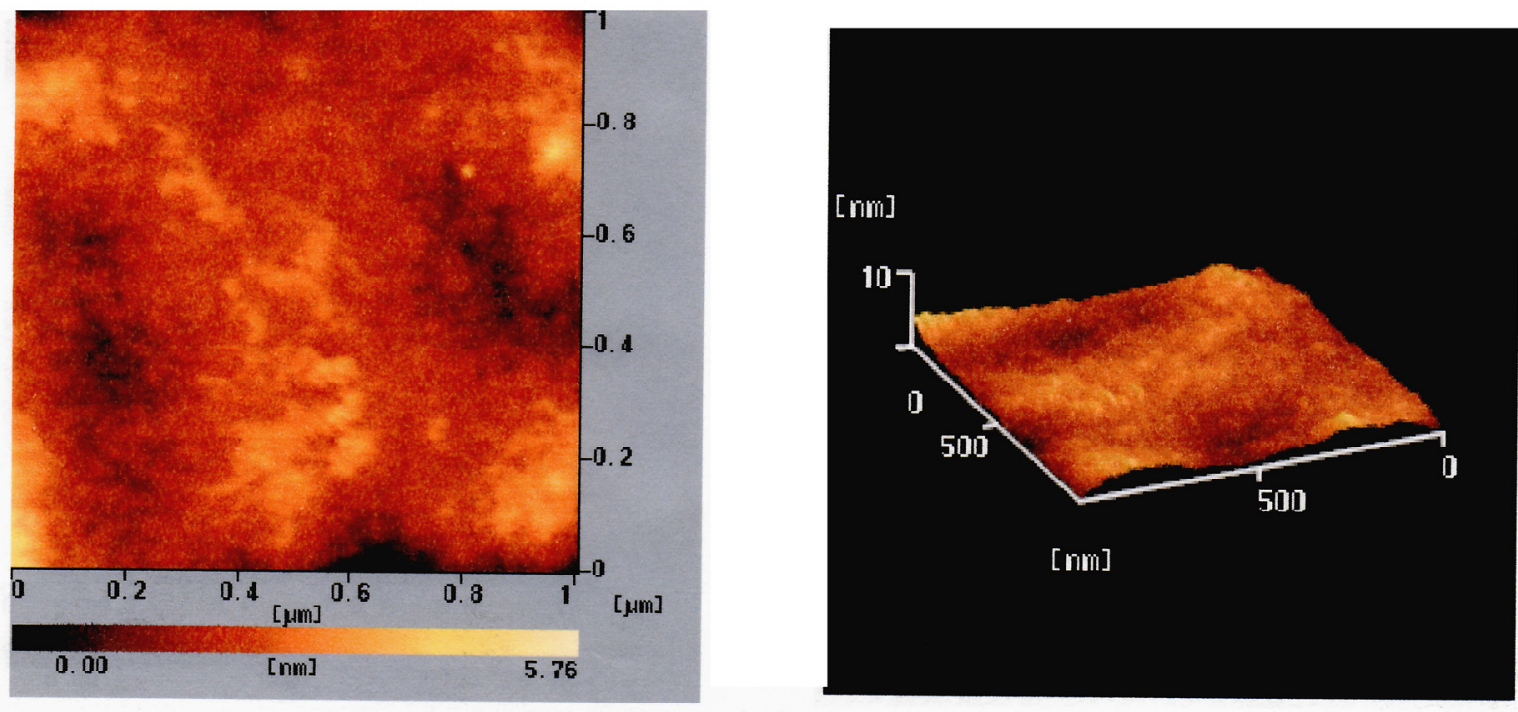

(a)
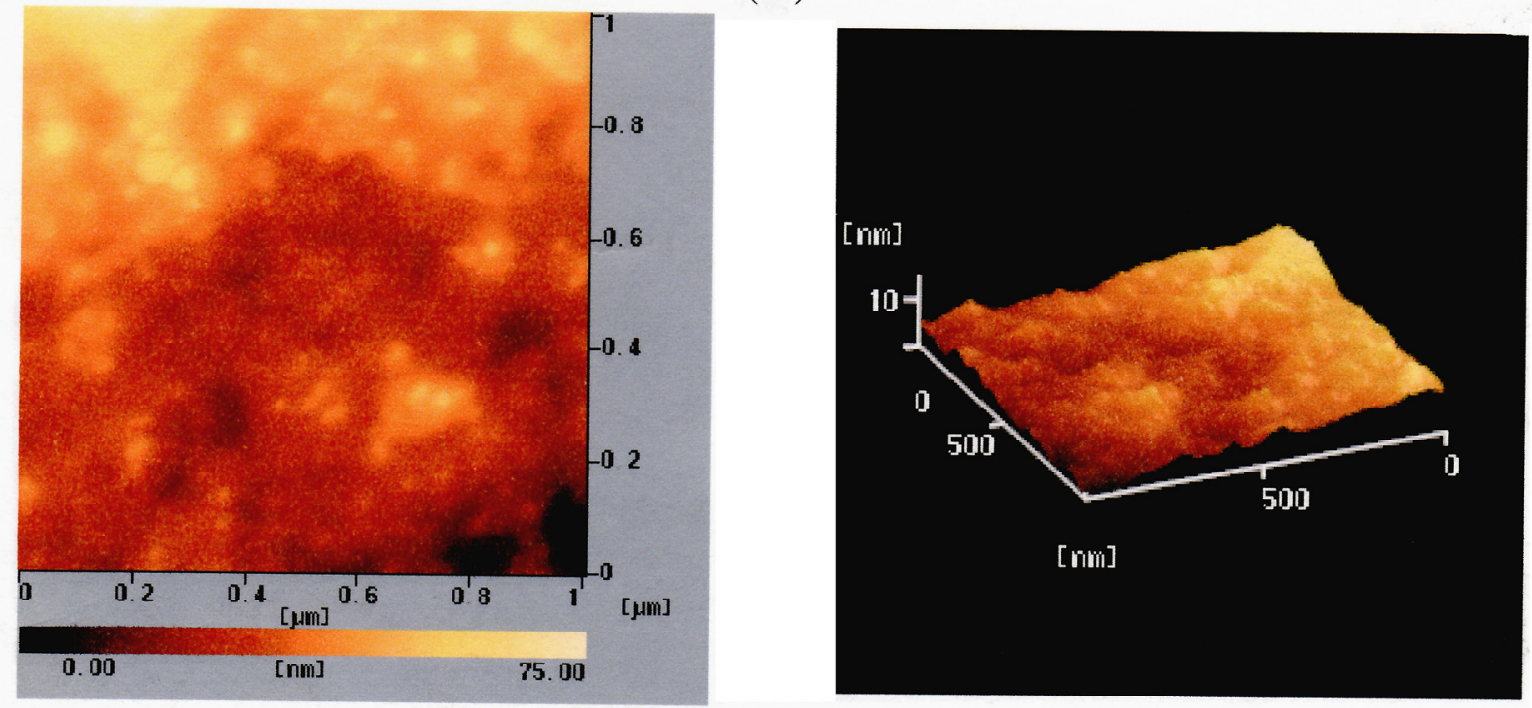

(b)

Fig. 11. The AFM morphology and 3D graph of coated film made from the free radical type photosensitive resin containing Mogul L carbon black at the loading amounts of (a) $5 \mathrm{wt} \%$ and (b) $15 \mathrm{wt} \%$, respectively.

Introduction of the dispersed solution of carbon black nano-particles into the polymeric resin composed from photo initiator and reactive monomer, the free radical type black photo-resist is prepared and coated by means of spinner on glass substrate to character its optical density and electric resistance. In general, the optical density of black matrix on color filter for STNLCD should larger than 2.5 per one $\mu \mathrm{m}$, but 3.0 per one $\mu \mathrm{m}$ of optical density is required to enhance color contrast and protect thin film transistor for TFT-LCD [24]. At loading amount of $10 \mathrm{w} t \%$ Mogul L and M900 carbon blacks, respectively, Fig. 8 displays the optical density per unit $\mu \mathrm{m}$ in film thickness of the free radical type photosensitive resin varying with the secondary average particle size. In the figure, it is observed that the optical density per unit $\mu \mathrm{m}$ in film thickness is increased with reducing the secondary average particle size of carbon black. This may be sketchily explained by Fig. 9, which indicates the smaller primary average particle size, the more light absorption by carbon black due to larger surface area under unit film thickness.

Fig. 10 presents the optical density per unit $\mu \mathrm{m}$ in film thickness varying with the loading content of carbon black in order to determine the minimum amount of Mogul L and M-900 carbon blacks, respectively, in free radical type photosensitive resin for the optical density more than 3 per one $\mu \mathrm{m}$ in film thickness. As shown in the figure, the minimum amounts are respectively $14.3 \mathrm{wt} \%$ and $10.9 \mathrm{wt} \%$ of Mogul L and M-900 carbon blacks in free radical type photo-resist. The reason for the low amount of carbon black might be explained in Figs. 11 and 12, respectively, which are AFM morphology of coated 

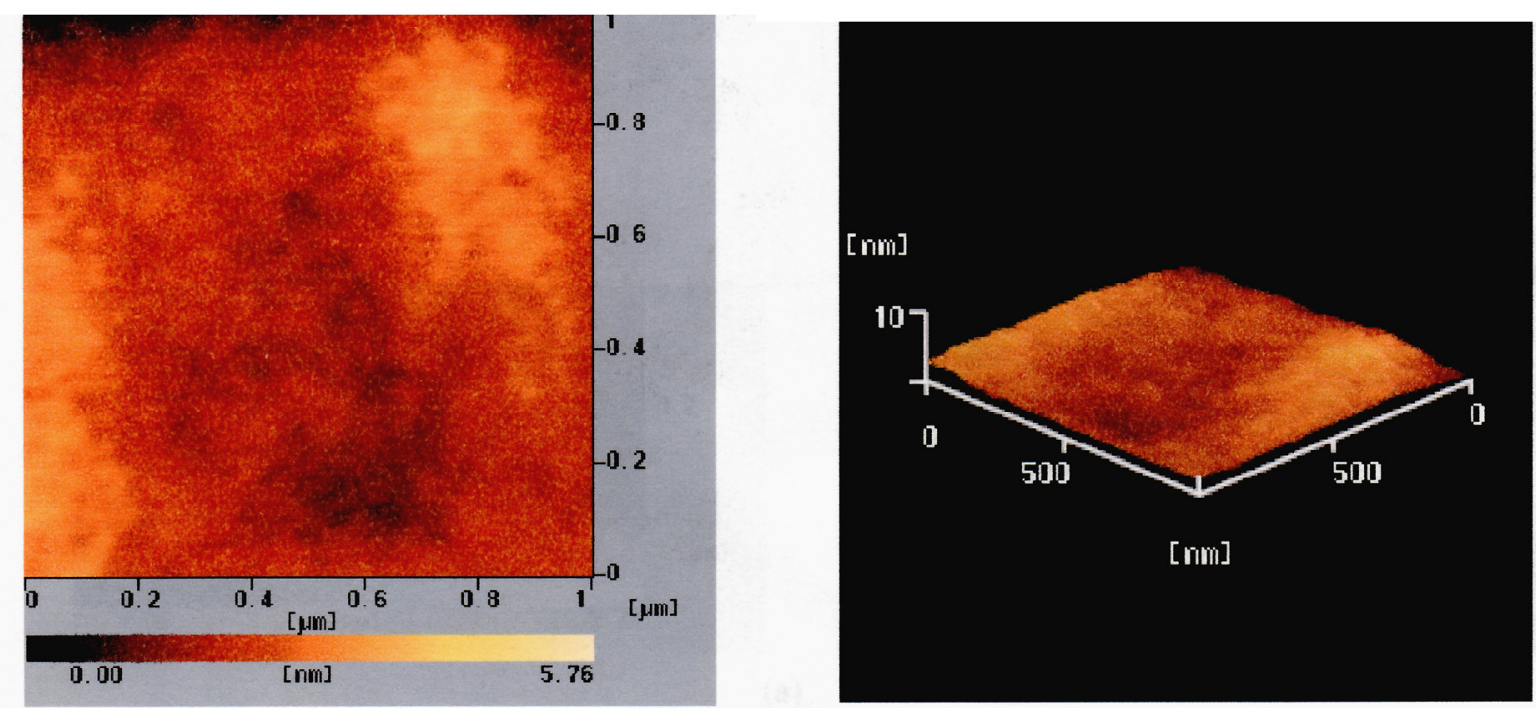

(a)
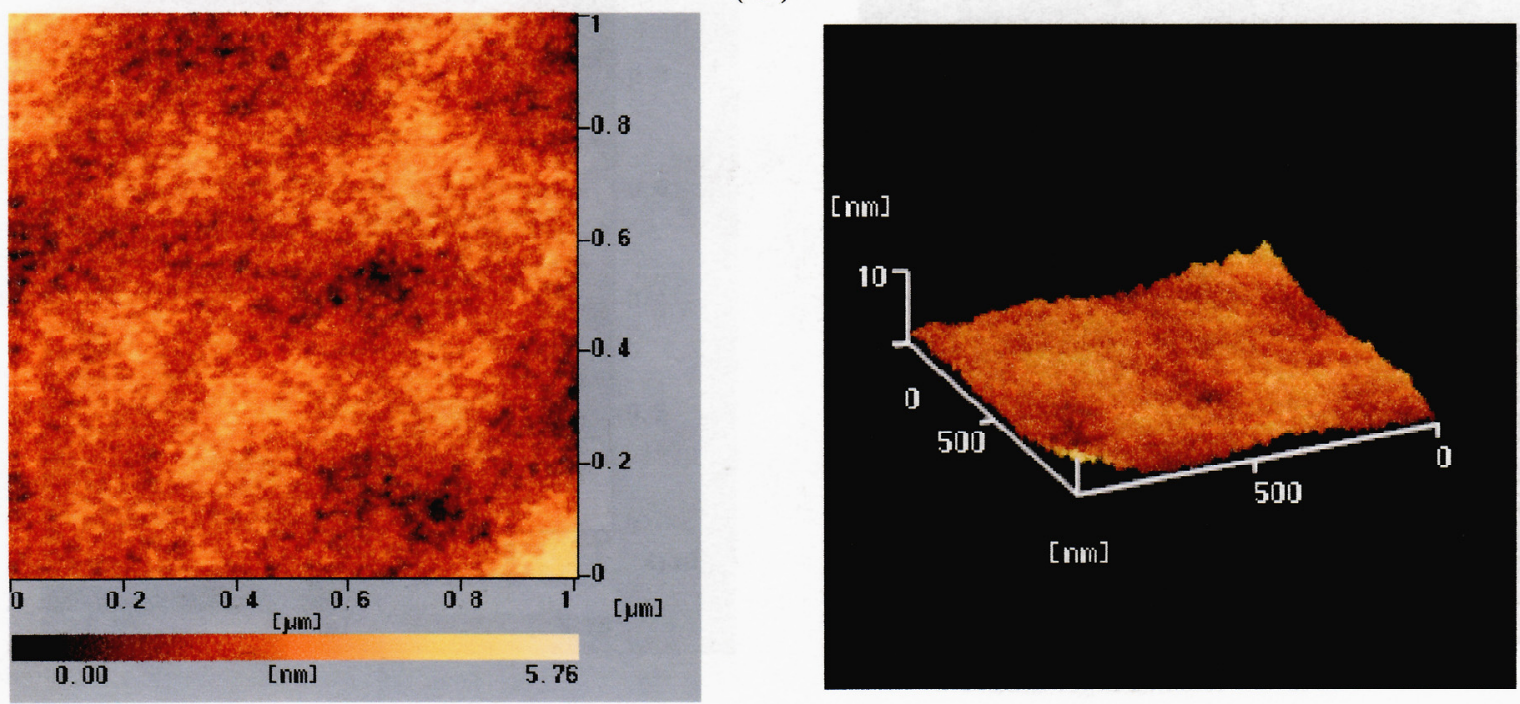

(b)

Fig. 12. The AFM morphology and $3 \mathrm{D}$ graph of coated film made from the free radical type photosensitive resin containing $M 900$ carbon black at the loading amounts of (a) $5 \mathrm{wt} \%$ and (b) $15 \mathrm{wt} \%$, respectively.

film made from the free radical type photo-resist containing $5 \mathrm{wt} \%$ and $15 \mathrm{wt} \%$ Mogul L and M900 carbon blacks on the glass substrate.

It could be observed that the film surface is gradually roughed with increasing carbon black content in resin. The surface roughness will reduce lithographic resolution of photo-resist due to scattering UV-light during the exposure. Therefore, it is necessary to reduce the loading amount of carbon black nano-particles in the free radical type photosensitive resin as soon as possible.

In addition, the surface electric resistance of black photo-resist is the important characteristic for in-plane switching (IPS) technology for the wide view angle of TFTLCD. The principle of IPS is to make liquid crystal

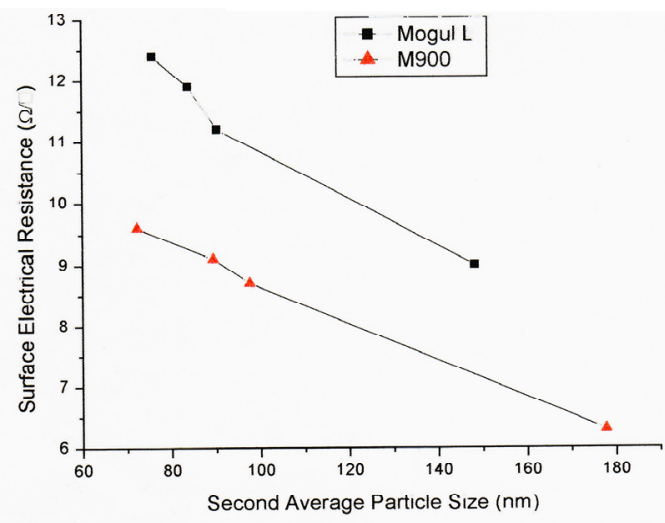

Fig. 13. The surface electric resistance varying with the secondary average particle sizes of Mogul L and M900 carbon blacks at the loading amount of 14.3 $w t \%$ and $10.9 w_{t} \%$, respectively, in free radical type photosensitive resin. 


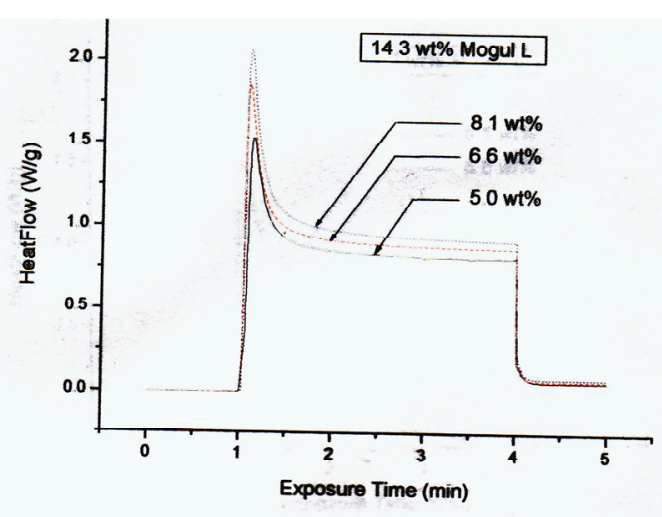

(a)

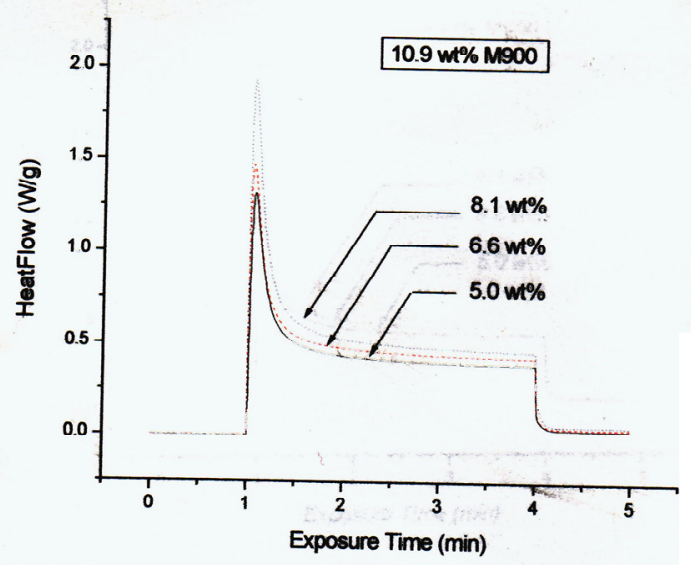

(b)

Fig. 14. The heat flow varying with exposing time during polymerization of free radical type photosensitive resin containing (a) $14.3 \mathrm{wt} \%$ Mogul L and (b) $10.9 \mathrm{wt} \% \mathrm{M} 900$ carbon blacks, respectively, in the different amounts of mixed photo-initiator.

molecules horizontally spinning to achieve light open and shut by supply a horizontal electric field. If black matrix on color filter has been characterized as the electric conductivity, it would present a vertical electric field and make liquid crystal molecules disorder.

Thus, black photo-resist should have high surface electric resistance for IPS LCD. In this work, the applications of surface modification and smaller secondary average particle size intend to reduce the surface electric resistance of carbon black in free radical type photosensitive resin. Fig. 13 shows the relationship of the surface electric resistance to the secondary average particle size of carbon black in resin matrix. It is discovered that the electric conductivity of M900 carbon black is higher than that of Mogul L carbon black in free radical type photosensitive resin. This may

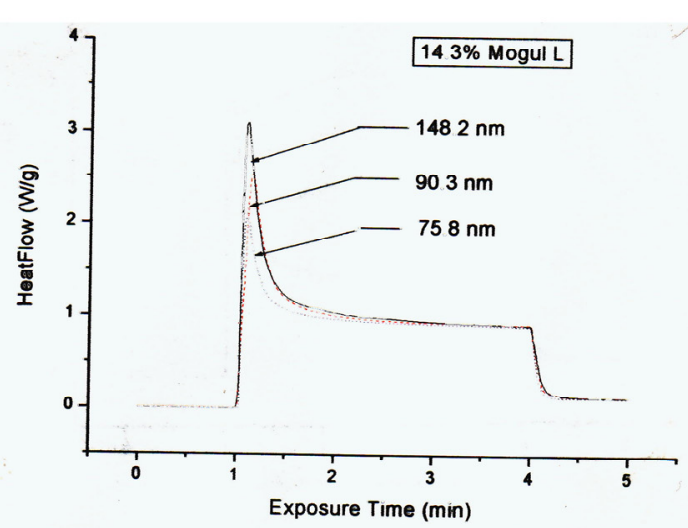

(a)

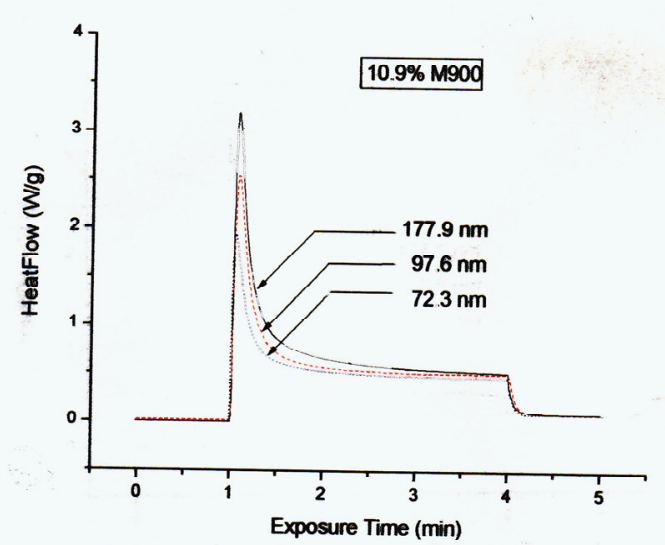

(b)

Fig. 15. The heat flow varying with exposing time during polymerization of free radical type photosensitive resin containing (a) $14.3 \mathrm{wt} \%$ Mogul L and (b) $10.9 \mathrm{wt} \%$ M900 carbon blacks, respectively, in the different secondary average particle sizes.

be caused by the different chemical modification on carbon blacks. The surface chemistry in terms of volatile content was usually employed to modify the carbon black with the functional groups like carboxyl, anhydride, ether, and phenol, for good properties such as dispersed stability, electric resistance, etc. As shown in specification, $5 w t \%$ and $2 w t \%$ of volatile contents adsorb on Mogul L and M900 carbon blacks, respectively. The type and loading amount of polymeric surfactant to form stereo structure stabilizing carbon black in the solution are also the important issues for high optical density but low electric conductivity of black matrix made from the free radical type 


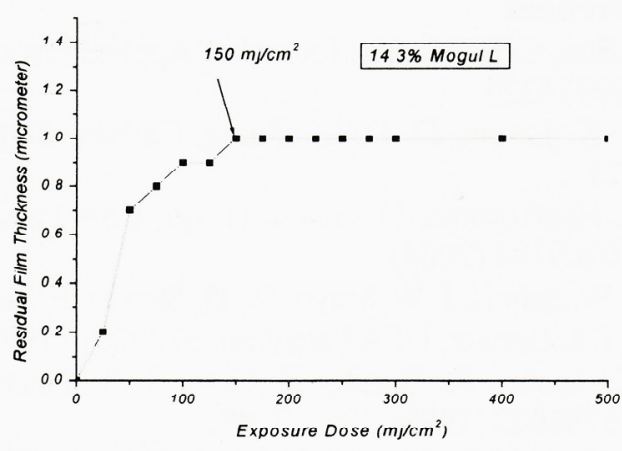

Wedge curve

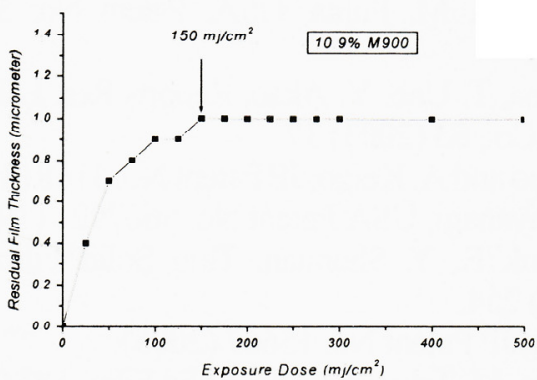

Wedge curve

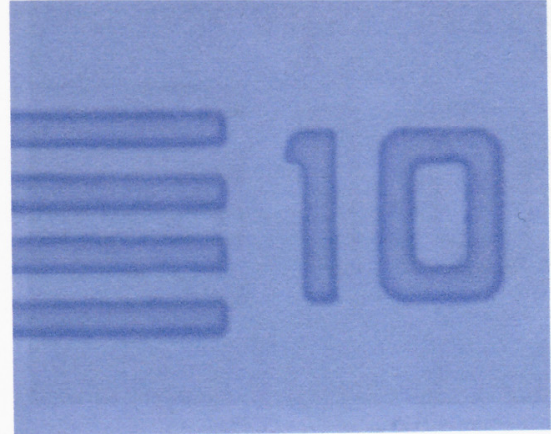

Pattern resolution $(\mu \mathrm{m})$

(a)

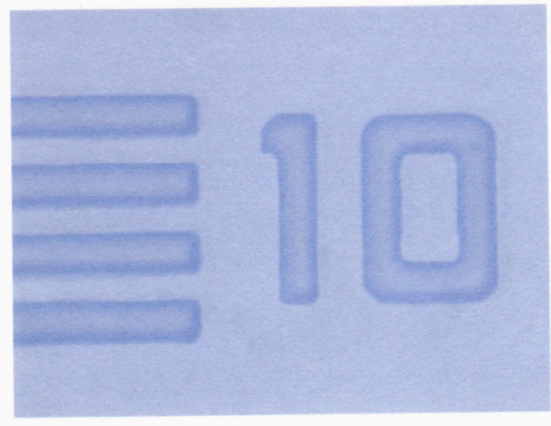

Pattern resolution $(\mu \mathrm{m})$

(b)

Fig. 16. The residual film thickness of free radical type photosensitive resin containing (a) $14.3 \mathrm{wt} \%$ Mogul $\mathrm{L}$ and (b) $10.9 \mathrm{wt} \%$ M900 carbon blacks, respectively, varying with exposing dose, as well as corresponding pattern resolution ( $\mu \mathrm{m})$ after development with $0.25 \% \mathrm{KOH}$ in de-ionic water for $45 \mathrm{sec}$.

photosensitive resin containing carbon black nano-particles. Future work is planned to study effects of treatment on carbon black and chemical component of surfactant on opto-electrical properties of the film made from photosensitive polymer.

\subsection{Photosensitivity}

The reactivity of free radical type photo-resist with carbon black nano-particle is detected by differential photo calorimeter, which the exothermic reaction of free radical type photosensitive resin containing carbon black nano-particles is monitored during UV light exposure. Fig. 14 shows the heat flow of photo-polymerization varying with exposure time in the different loading amount of mixed photo-initiator composed from CGI-242 and Irgacure 369 in the black photo-resist. $\Lambda$ s shown in the figure, the reactivity of free radical type black photo-resist can be enhanced with increasing the amount of mixed photo-initiator, but slowed with reducing the secondary average particle size of carbon black due to effects of UV-visible light shielding and absorption in resin matrix, as demonstrated in Fig. 15. As a result, it is necessary to regular the loading amount of photo-initiator and secondary average particle size of carbon black in the optimal reactivity of free radical type photosensitive resin for high resolution of black matrix.

\subsection{Wedge curve analysis}

Photolithographic performance of free radical type photosensitive resin with carbon black nano-particles is carried out by the analysis of the wedge curve.

Fig. 16 demonstrates the residual film thickness of free radical type photosensitive resin containing 14.3 $\mathrm{wt} \%$ of Mogul L and 10.9wt $\%$ of M900 carbon blacks, respectively, varying with exposure dose, which resolution $(\mu \mathrm{m})$ in line width fabricated through a radiation of $150 \mathrm{~mJ} / \mathrm{cm}^{2}$ followed by development with $0.25 \mathrm{wt} \% \mathrm{KOH}$ in de-ionic water for $45 \mathrm{sec}$. As shown aforementioned in Figs.10 and 13, the 10 $\mu$ m resolution in line width of free radical type photo-resist containing (a) $14.3 \mathrm{wt} \% \mathrm{Mogul} \mathrm{L}$ and (b) $10.9 \mathrm{wt} \% \mathrm{M}-900$ carbon 
blacks can be realized for optical density more than 3 per unit $\mu \mathrm{m}$ and surface electrical resistance large than $1 \times 10^{9} \Omega$ square. In addition, the free radical type photosensitive resin with $14.3 \mathrm{wt} \%$ and $10.9 \mathrm{wt} \%$ carbon blacks with the second average particle sizes of $75.8 \mathrm{~nm}$ and $72.3 \mathrm{~nm}$, respectively, can be completely cross-linked by an radiation of $150 \mathrm{~mJ} / \mathrm{cm}^{2}$ without film loss after the developing process.

\section{Conclusion}

Having well dispersed carbon black nano-particle in polymeric resin containing mixed photo-initiator and reactive monomer, the free radical type photosensitive resin with carbon black nano-particles, at low loading amount, stabilized by polymeric surfactant can be suggested for high resolution of black matrix with higher optical density but lower electrical conductivity. Some remarks are highlighted as follows:

(1)Dispersion of carbon black nano-particle may be stabilized in both the solution and photosensitive resin in the presence of polymeric surfactant.

(2)Black matrix with optical density more than 3 per unit film thickness and surface electrical resistance more than $1 \times 10^{9} \Omega /$ square can be achieved by the free radical type photosensitive resin containing $10.9 \mathrm{wt} \%$ carbon black with functional treatment in the secondary average particle of $72 \mathrm{~nm}$.

(3)The loading amount of mixed photo-initiator and secondary average particle size of carbon black are critical issues for the optimal reactivity of free radical type photosensitive resin in high resolution of black matrix.

(4)The resolution of $10 \mu \mathrm{m}$ in line width can be obtained by free radical type photosensitive resin containing $14.3 \%$ carbon black in secondary average particle size of $75.8 \mathrm{~nm}$ through an exposure of 150 $\mathrm{mJ} / \mathrm{cm}^{2}$ followed by the development of $0.25 \mathrm{wt} \%$ $\mathrm{KOH}$ in de-ionic water for $45 \mathrm{sec}$ in this work.

\section{Acknowledgements}

The authors would like to gratefully acknowledge the measurement supports of photo differential scanning thermo-grams by Material and Chemical Research Laboratory, Industrial Technology of Research Institute, Taiwan, R. O. C.

\section{References}

1. S. Sun, C. B. Murray, Journal of Applied Physics, 85 (1999) 4325.

2. C. K. Leong, D. D. L. Chung, Carbon, 42 (2004) 2323.

3. A. Hatakeyama, H. Gotoh, H. Ito. USA Patent No. 0209184 (2004).

4. R. W. Sabnis, J. W. Mayo, M. D. Stroder, E. G Hays, T. L.Brewer, USA Patent no. 5780201 (1998).

5. K. Inoue, F. Tomitr, T. Goto. U.S. Patent No. 5786042 (1998).

6. K. Hayashi, K. Iwasaki, H. Morii, S. Horie, JP Patent No. 5148223 (2005).

7. R. W. Sabnis, Displays, 20 (1999), 119.

8. J. Fujikawa, Y. Limura, M. Takahashi, T. Nishimoto, H. Matsui, M. Fujita, USA. Patent No. 5592317 (1997).

9. T. Hiruma, T. Uno, Y. Akao, Reports Res. Lab. Asahi Glass Co., 53 (2003) 37.

10. M.Yasuo and A. Keigo, JP Patent No. 316813 (2001).

11. T. Takayanagi, USA Patent No. 5667921 (1997).

12. S. Frank F., Y. Shuhuan, Thin Solid Film, 322 (1998) 254.

13. S. Toda, JP Patent No. 15667 (2005).

14. N. Ando, M. Takeuchi, Thin Solid Film, 182 (1998) 334.

15. I. Sohko, E. Patent No.1120446 (2001).

16. M. masayuki, K. Miharu, I. Sohko, Y. Yatsuya, E. Patent No.1479732 (2004).

17. Y. Shima, T. Taguchi, A. Tamura, USA Patent No. 5925484 (1999).

18. S.L. Draper, G.A. Montero, B. Smith, K. Beck, Dyes and Pigments, 45 (2000) 177.

19. J. B. Hannay, J. Hogarth, Proc. R. Soc. London, 1979.

20. U. Kiyoshi, S. Masaru, K. Hiroshi, USA Patent No. 5714286 (1998).

21. E. Reuter, S. Silber, C. Psiorz, Progress in Organic Coatings, 37 (1999) 161.

22. Y. Hideaki, K. Takehide, N. Takashi. USA Patent No. 6514644 (2003).

23. H. Saikatsu, S. Sakamoto, M. Takakamo, USA Patent No. 0048384 (2005).

24. S. Dan, N. Suzuki, T. Mouri, USA Patent No. 6171733 (2001).

25. R. W. Sabnis, J. W. Mayo, M. D. Stroder, K. Aoba, K. Ema, Y. Sone, T. Nihira, A. Yangimoto, Asia Display, 1998, p. 1025.

26. T. Hasumi, T. Koseki, M. Kodate, K. Shimizu, Euro. Display, 1996, 237.

27. L. Vaisman, G Marom, H. Daniel Wagner, Adv. Funt. Mater., 16 (2006) 357.

28.. J. Accorsi, E. Romero, Plastics Engineering, 1995, p. 29.

29. G. F. Cerofolini, L. Meda, Journal of Colloid and Interface Science, 202 (1998), 104. 